\title{
ORIGINAL ARTICLE The effect of mirodenafil on the penile erection and corpus cavernosum in the rat model of cavernosal nerve injury
}

\author{
$\mathrm{H} \mathrm{Kim}^{1}$, DW Sohn ${ }^{1}$, SD Kim² ${ }^{2}$ S-H Hong ${ }^{1}$, HJ Suh ${ }^{1}$, CB Lee ${ }^{1}$ and SW Kim ${ }^{1}$ \\ ${ }^{1}$ Department of Urology, College of Medicine, The Catholic University of Korea, Seoul, Korea and ${ }^{2}$ Department of Urology, \\ College of Medicine, The Jeju National University of Korea, Jeju, Korea
}

\begin{abstract}
Impotence is one of the common complications after the radical prostatectomy. One of the main reasons of this complication is due to the dysfunction of the veins in corpus cavernosum. Recent studies have shown that the erectile function is improved after the long-term therapy of phosphodiesterase type 5 inhibitor among patients with post-prostatectomy erectile dysfunction. In this study, we evaluated the effects of mirodenafil on the penile erection and corpus cavernosum tissues in the rat model of cavernosal nerve injury. Rats were divided into four groups: (1) control group, (2) bilateral cavernosal nerve injury group, (3) mirodenafil $10 \mathrm{mg}$ therapy group after the nerve injury and (4) mirodenafil $20 \mathrm{mg}$ therapy group after the nerve injury. After we identified the nerve from the pelvic nerve complex on the lateral side of the prostate, the rats in the control group were sutured without causing any nerve injury and in other groups we damaged the nerve by compressing it with a vessel clamp. Then, 10 and $20 \mathrm{mg} \mathrm{kg}^{-1}$ of mirodenafil were orally administered to two experimental groups. After 8 weeks, the intracavernosal pressure (ICP) was recorded. The immunohistochemical staining and western blot were performed, and the effect of mirodenafil on the expression of cyclic guanosine monophosphate (cGMP) was evaluated through enzyme-linked immunosorbent assay. The ICP of nerve-injured group was decreased compared with the control group; however, the ICP of the mirodenafil-administered groups was improved compared with the nerve-injured group. The Masson's trichrome staining confirmed that the smooth muscle (SM) component was increased in the mirodenafil-administered groups. The nitric oxide synthase expression and cGMP of mirodenafil-administered groups was increased compared with the nerve-injured group. Long-term therapy of mirodenafil may improve the erectile function after the radical prostatectomy by preserving the SM content and inhibiting the fibrosis of the corpus cavernosum.
\end{abstract}

International Journal of Impotence Research (2010) 22, 291-297; doi:10.1038/ijir.2010.19;

published online 23 September 2010

Keywords: mirodenafil; corpus cavernosum; erectile dysfunction

\section{Introduction}

With the advancement in early detection of the prostate cancer, radical prostatectomy has been frequently performed. Although more surgical advances in prostatectomy such as robot-assisted surgery have been made, complications such as erectile dysfunction and urinary incontinence occur frequently after the radical prostatectomy. ${ }^{1,2}$

Correspondence: Professor SW Kim, Department of Urology, The Catholic University of Korea, Seoul St Mary's Hospital, BanPoDong 505, Seoul 150-713, Republic of Korea.

E-mail: ksw1227@catholic.ac.kr

Received 21 September 2009; revised 15 April 2010; accepted 24 May 2010; published online 23 September 2010
Moreover, the number of patients who experience the postsurgical complications is gradually increasing, despite the fact that the patient's age at the time of prostate cancer diagnosis is decreasing. The factors that affect the occurrence of the postsurgical complications are surgical dexterity, degree of anatomical variability and progression of disease. For the prevention of the post-prostatectomy erectile dysfunction, many surgical procedures and modalities are being researched and developed. For instance, sparing nerves in the vicinity of the prostate during the radical prostatectomy was considered to reduce the complications. ${ }^{3}$ In cases in which the nerve sparing surgery is not indicated, erectile dysfunction and other complications do frequently occur. Nevertheless, more than half of the patients who received the nerve-sparing operations complained of a partial erectile dysfunction. ${ }^{4}$ 
The primary cause of this phenomenon was because of the corporal veno-occlusive dysfunction, which is the inability of the corporal smooth muscle (SM) cells to relax sufficiently to attain intracorporal pressure great enough to adequately compress the subtunical veins and prevent venous leakage. ${ }^{5,6}$

In terms of treating the erectile dysfunction, recent studies have shown that a long-term use of phosphodiesterase type 5 (PDE5) inhibitors improves the erectile function. ${ }^{7-9}$ Treatment agents for the erectile dysfunction include sildenafil, tadalafil, vardenafil and udenafil. Up to this date, only a small number of studies have reported their effects on the erectile dysfunction from any kinds of nerve injury. One of the recently developed PDE5 inhibitors, mirodenafil, has been reported to have an excellent profile of the efficacy for the erectile dysfunction; yet, there are no studies confirming its effects on the erectile function among postprostatectomy patients. ${ }^{10-13}$ In an animal experimental model of the nerve injury in corpus cavernosum, we administered mirodenafil to evaluate its effects on the erectile function and corpus cavernosum tissues. These results would serve as the foundation for the possibility of administering mirodenafil and other PDE5 inhibitors in treating patients with postprostatectomy erectile dysfunction.

\section{Materials and methods}

\section{Materials}

White male Sprague-Dawley rats aged 16 weeks with weight distribution of $300-350 \mathrm{~g}$ were purchased from Samtako Inc. (Osan, Korea). Then, the rats were divided into four groups: the control group ( $n=10$, group 1$)$, the bilateral nerve injury group $\left(n=10\right.$, group 2), the mirodenafil $10 \mathrm{mg} \mathrm{kg}^{-1}$ administered group after the bilateral nerve injury ( $n=10$, group 3 , M10 group) and the mirodenafil $20 \mathrm{mg} \mathrm{kg}^{-1}$ administered group after the bilateral nerve injury ( $n=10$, group 4 , M20 group).

\section{Experimental animals}

Tiletamine (Zoletil) $0.2 \mathrm{ml}$ was intra-abdominally injected to anesthetize the animals. A median incision was made on the lower abdomen, thereby exposing the urinary bladder and prostate. After identifying the location of pelvic nerve plexus on the lateral side to bilateral prostates, the posterolateral nerve branch was dissected. The nerve was damaged by compressing it for $2 \mathrm{~min}$. Technically in the strict sense, we damaged the nerve by compressing it with a clamp (nerve crush), rather than severing the nerve as other studies have injured the nerve (nerve cutting). In group 1 (control group), same procedure was carried out for identifying the nerve plexus and the suture was performed without causing any nerve injury. In group 2 (nerve injury group or BCNX group), the suture was performed after causing the nerve injury. Mirodenafil (SK Chemicals, Suwon, Korea) was dissolved in drinking water as described previously. ${ }^{10}$ Mirodenafil was dissolved in $40 \%$ PEG solution in water and the rats were fasted overnight before drug administration and until $6 \mathrm{~h}$ after dosing. The drinking volume and the body weight were recorded daily.

In group 3 (M10 group), $10 \mathrm{mg} \mathrm{kg}^{-1}$ of mirodenafil was orally administered. In group 4 (M20 group), twice the dosage of mirodenafil $\left(20 \mathrm{mg} \mathrm{kg}^{-1}\right)$ was orally administered. After 8 weeks, erectile function was measured using the intracavernosal pressure (ICP). Corpus cavernosum tissue sampling was performed followed by the Masson's trichrome staining, NOS expression (western blot) and cyclic guanosine monophosphate (cGMP) analysis.

\section{ICP measurement}

The rats were anesthetized with an intraperitoneal injection of $0.2 \mathrm{ml}$ tiletamine (Zoletil). With the rat in the supine position, the penis was dissected and the corpus cavernosum and crus of the penis were exposed. A low, midline abdominal incision was made to access the pelvis, and the pelvic ganglion lateral to the right prostate was exposed. For the measurement of the ICP, a heparinized $23 \mathrm{G}$ butterfly needle was inserted in the corpus cavernosum of penile proximal portion after penile skin was degloved and the corpus cavernosum identified. Then a bipolar electrical stimulator was placed on the ganglion to stimulate the cavernosal nerve for $50 \mathrm{~s}$ at $10 \mathrm{~V}$ and $2.4 \mathrm{~mA}$ for $0.5 \mathrm{~ms}$. The cavernosal nerve stimulation was conducted at least three times and the interval between stimulations was maintained for over $10 \mathrm{~min}$. After the stimulation test, the corpus cavernosum was removed and divided into two. The first part was cryopreserved in liquid nitrogen and the other part was fixed in formalin. To compare the erections of the control and experimental groups, we recorded the peak ICP. The 'drop rate' was determined by recording the decrease in ICP within the next $1 \mathrm{~min}$ after the infusion was stopped.

\section{Masson's trichrome staining}

After cavernosometry, the skin denuded middle part of the penile shafts were fixed overnight in $10 \%$ formalin, washed and stored in $70 \%$ alcohol at $4{ }^{\circ} \mathrm{C}$ until processed for paraffin-embedded tissue sectioning $(5 \mu \mathrm{m})$. The cavernosal tissue was obtained for the Masson's trichrome staining. After staining, the color distribution of the muscle tissue was approximated by using the Adobe Photoshop CS 8.0 (San Jose, CA, USA). After the entire color distribution of the image was calculated, we 
selected the muscle tissue distribution, expressed as the color red. There were somewhat standard deviations in our calculation because of color overlays and ambiguity of the color spectrum of the muscle tissues.

\section{eNOS and nNOS protein expression tests: western \\ blot}

The skin, dorsal vein and urethra of all rats were removed. The corpus cavernosum was obtained from all rats and homogenized individually in a buffer solution of $0.32 \mathrm{M}$ sucrose, $0.2 \mathrm{M}$ HEPES $(\mathrm{pH}$ 7.4), $1 \mathrm{mM}$ ethylenediaminetetraacetic acid, $1 \mathrm{mM}$ dithiothreitol, $10 \mu \mathrm{g} \mathrm{ml}^{-1}$ leupeptin, $2 \mu \mathrm{g} \mathrm{ml}^{-1}$ aprotinin, $1 \mu \mathrm{g} \mathrm{ml}^{-1}$ pepstatin, $10 \mu \mathrm{g} \mathrm{ml}^{-1}$ trypsin inhibitor and $1 \mathrm{~mm}$ phenylmethylsulfonyl fluoride. The homogenized buffer solution was placed on ice for $15 \mathrm{~min}$ and centrifuged at $4{ }^{\circ} \mathrm{C}$ for 13000 r.p.m. for 15 min. The supernatant solution was separated. The separated solution was used in the bovine serum albumin. Quantitative protein $(30 \mu \mathrm{g})$ was denatured at $95{ }^{\circ} \mathrm{C}$ for $5 \mathrm{~min}$ and electrophoresis was performed on a $12 \%$ discontinuous SDS-polyacrylamide gel. The proteins were then electroblotted onto a $0.2 \mu \mathrm{m}$ polyvinylidene difluoride (Amersham Biosciences, Piscataway, NJ, USA) membrane for $150 \mathrm{~min}$ at $25 \mathrm{~V}$. The membranes were reacted with blocking buffer ( $5 \%$ skim milk in TBS-T buffer) for $30 \mathrm{~min}$ at the ambient temperature. The endothelial NOS (eNOS) and neuronal NOS (nNOS) (BD Biosciences, San Diego, CA, USA) antibodies were added for $2 \mathrm{~h}$, and the membrane was washed three times using TTBS at intervals of $10 \mathrm{~min}$. As the secondary antibodies, anti-mouse IgG-HRP and antigoat IgG-HRP (1:2000 dilution) (Zymed Laboratories, San Francisco, CA, USA), were added at the ambient temperature for $1 \mathrm{~h}$ and the membrane was washed again with TTBS for six times with an interval of 5 min between each washing. Chemiluminescence was detected using ECL western blotting detection reagents. Densitometric assessment of the bands on the autoradiogram was performed using Bio1D software (version 97; Vilber Lourmat, Marne-la-Vallée, France).

\section{cGMP analysis}

The corpora cavernosa was immediately frozen in liquid nitrogen. The frozen sample was homogenized in cold $6 \%(\mathrm{w} / \mathrm{v})$ trichloroacetic acid at $2-8{ }^{\circ} \mathrm{C}$ to produce a $10 \%(\mathrm{w} / \mathrm{v})$ homogenate. Each homogenized penis sample was centrifuged at $2000 \times \mathrm{g}$ for $15 \mathrm{~min}$ at $4{ }^{\circ} \mathrm{C}$ and recovered the supernatant. The supernatant was washed four times with 5 volumes of water saturated diethyl ether and dried at $60^{\circ} \mathrm{C}$. The dried extract was dissolved in a suitable volume of assay buffer before analysis. After the dissolution, the samples were assayed for cGMP by using a cGMP competitive enzyme immunoassay kit (Biotrak; Amersham Pharmacia Biotech UK, Bucks, UK).
Effect of mirodenafil on erection and corpus cavernosum

\section{Statistical analysis}

All the measurements were expressed as mean \pm standard deviation (s.d). Statistical analysis was obtained through Sigma stat for Windows. An intergroup comparison was made with the use of Newman-Keuls multiple comparison test. The cutoff value of statistical significance was $P<0.05$.

\section{Results}

Changes in the erectile function after the nerve injury

The erectile function was measured 8 weeks after the nerve injury. As a result, the erectile function was decreased in the nerve injury group (drop rate, $31 \pm 2.3 \mathrm{~mm} \mathrm{Hg} \mathrm{min}^{-1}$ ) compared with the control group ( $9 \pm 1.5 \mathrm{~mm} \mathrm{Hg} \mathrm{min}^{-1} ; P<0.05$ ) (Table 1).

Changes in the erectile function after the administration of mirodenafil

The erectile function was measured 8 weeks after the nerve injury. The erectile function was significantly improved in mirodenafil treatment groups, M10 group (15 $\pm 5.9 \mathrm{~mm} \mathrm{Hg} \mathrm{min}^{-1}$ ) and M20 group (12 \pm $\left.6.9 \mathrm{~mm} \mathrm{Hg} \mathrm{min}^{-1}\right)$, compared with the nerve injury group (31 $\pm 2.3 \mathrm{~mm} \mathrm{Hg} \mathrm{min}^{-1} ; P<0.05$ ) (Table 1).

\section{Decreased muscle content and increased collagen content}

On the Masson's trichrome staining, the muscle content was decreased and collagen content was increased in the nerve injury group as compared with the control group (Figure 1, Table 2). In the mirodenafil-administered groups (10.6 $\pm 5,14.0 \pm 7$ ), the muscle/collagen ratio was higher than the nerve injury group (6.0 \pm 3$)$ (Figure 1, Table 2).

\section{Quantification of eNOS and nNOS proteins}

In all groups, the expression of NOS against actin was different and so we needed the correction to compare the expression of NOS. We corrected the

Table 1 Changes of ICP at 8 weeks after cavernosal nerve injury

\begin{tabular}{|c|c|c|c|c|c|c|}
\hline & \multicolumn{2}{|c|}{$\begin{array}{l}\text { Flaccid ICP } \\
\quad(\mathrm{mm} \mathrm{Hg})\end{array}$} & \multicolumn{2}{|c|}{$\begin{array}{c}\text { ICP after } \\
\text { papaverine }(\mathrm{mm} \mathrm{Hg})\end{array}$} & \multicolumn{2}{|c|}{$\begin{array}{c}\text { Drop rate } \\
\left(\mathrm{mm} \mathrm{Hg} \mathrm{min}^{-1}\right)\end{array}$} \\
\hline & Mean & s.d. & Mean & s.d. & Mean & s.d. \\
\hline Control & 9 & 2.2 & 80 & 5.8 & 9 & 1.5 \\
\hline BCNX & 7 & 1.1 & 55 & 6.7 & $31^{\mathrm{a}}$ & 2.3 \\
\hline M10 & 11 & 2.0 & 61 & 5.4 & $15^{\mathrm{b}}$ & 5.9 \\
\hline M20 & 14 & 2.4 & 68 & 6.3 & $12^{\mathrm{b}}$ & 6.9 \\
\hline
\end{tabular}

\footnotetext{
${ }^{\mathrm{a}}$ Significantly increased $(P<0.05)$ compared with control group.

$\mathrm{b}^{\mathrm{b}}$ Significantly decreased $(P<0.05)$ compared with BCNX group.
} 

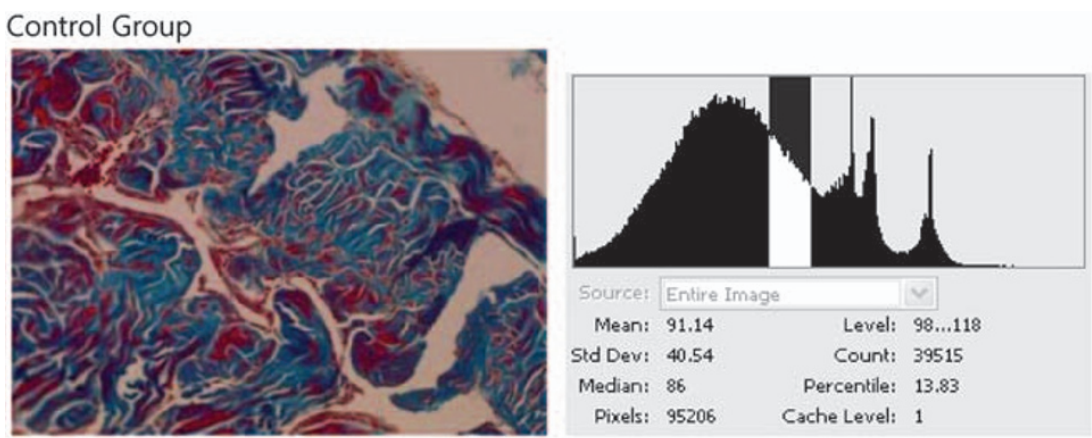

\section{BCNX Group}
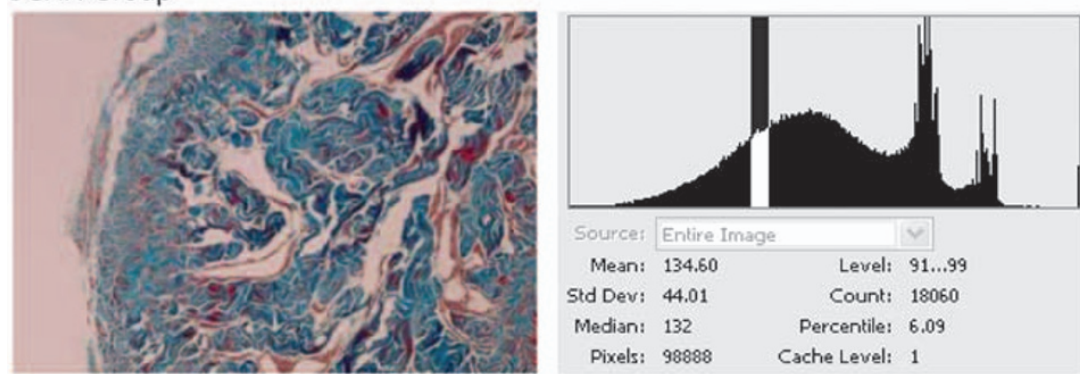

\section{M10 Group}
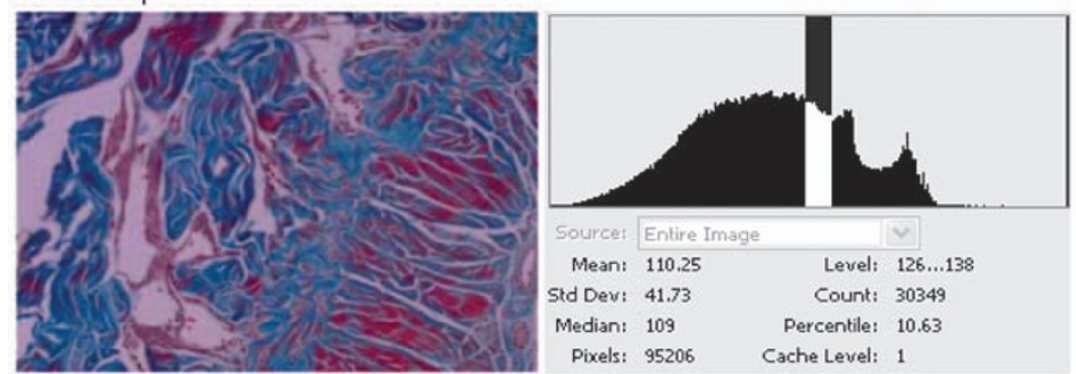

M20 Group
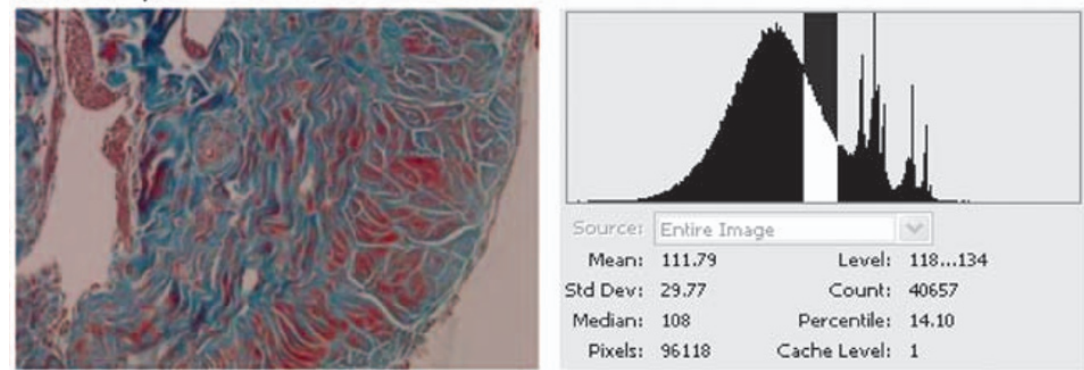

Figure 1 Masson's trichrome staining for collagen (blue) and smooth muscle $(\times 100)$. Control group, normal group; BCNX group, cavernosal nerve injury group; M10 group, mirodenafil $10 \mathrm{mg} \mathrm{kg}^{-1}$ administered group intake after cavernosal nerve injury; M20 group, mirodenafil $20 \mathrm{mg} \mathrm{kg}^{-1}$ administered group after cavernosal nerve injury.

expression of NOS against actin as 100 and compared the expression of NOS. eNOS and nNOS proteins were decreased by western analysis in the nerve crush group as compared with the control group, and levels increased in the mirodenafil treatment groups (Figures 2 and 3$)(P<0.05)$.

\section{Effect of mirodenafil on $c G M P$}

cGMP was significantly decreased in the nerve injury group $(20.8 \pm 5.0 \mathrm{fmol}$ per well) compared
Table 2 Muscle distribution (muscle/collagen ratio) at 8 weeks after cavernosal nerve injury

Muscle distribution (muscle/collagen ratio)

\begin{tabular}{lcc}
\cline { 2 - 3 } Group & Mean (\%) & s.d. \\
\hline Control & 13.8 & 7 \\
BCNX & 6.0 & 3 \\
M10 & 10.6 & 5 \\
M20 & 14.0 & 7 \\
\hline
\end{tabular}



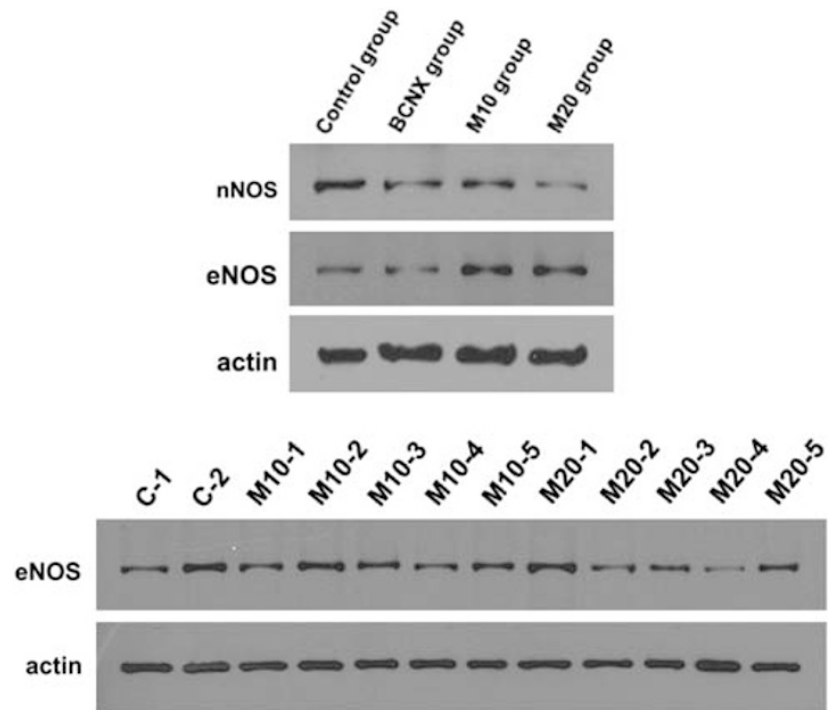

Figure 2 The expression of NOS at 8 weeks after cavernosal nerve injury.

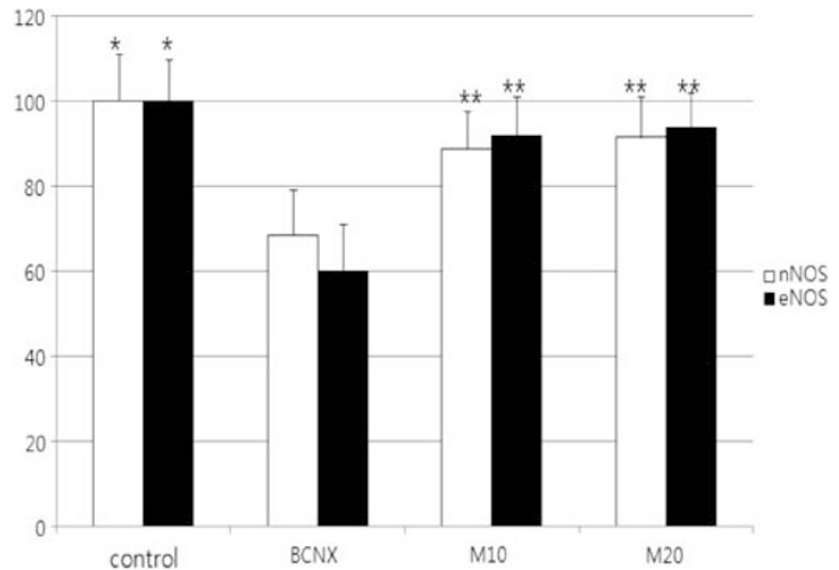

Figure 3 The expression of NOS at 8 weeks after cavernosal nerve injury. ${ }^{*}$ Significantly different $(P<0.05)$ from the BCNX group. ${ }^{* *}$ Significantly different $(P<0.05)$ from the BCNX group.

with the control group. cGMP in M10 group (36.4 \pm $15.7 \mathrm{fmol}$ per well) and in M20 group (59.8 \pm $17.0 \mathrm{fmol}$ per well) was increased compared with the nerve injury group (Figure 4$)(P<0.05)$.

\section{Discussion}

Neurotransmitters that induce the penile erection are nitric oxide (NO), acetylcholine, substance $\mathrm{P}$, vasoactive intestinal peptide and adenosine triphosphate in the penile nerve; and NO, prostaglandin and bradykinin in the corpus cavernosum. ${ }^{14,15}$ Specifically, NO is known as the most important neurotransmitter that mediates the relaxation of SM layer present in the corpus cavernosum. ${ }^{16,17}$ Synthesized within the vascular endothelium, NO
Effect of mirodenafil on erection and corpus cavernosum H Kim et al

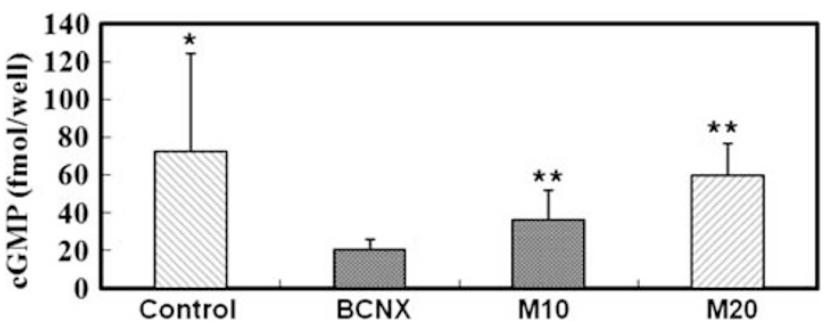

Figure 4 The effect of mirodenafil on cGMP at 8 weeks after cavernosal nerve injury. ${ }^{*}$ Significantly increased $(P<0.05)$ compared with BCNX group. ${ }^{*}$ Significantly increased $(P<0.05)$ compared with BCNX group.

is an endothelium-derived relaxation factor in which nitric oxide synthase (NOS) has an important role in its metabolism. NO is diffused through the cell membrane and activates guanylate cyclase $\mathrm{SM}$ in vessel in the adjacent corpus cavernosum. Consequently, it increases the synthesis of cGMP, mediating the relaxation of corpus cavernosum. ${ }^{17}$ It has been reported that constitutive NOS (eNOS) and inducible NOS are located within the vascular endothelium. ${ }^{18}$ It is known that inducible NOS directly decreases collagen deposition or suppresses the formation of profibrotic reactive oxygen species, thereby having an anti-fibrotic effect. ${ }^{19,20}$ The role of NOS has been frequently examined in association with the erectile dysfunction after the extensive prostatectomy. Causative factors for the erectile dysfunction after the prostatectomy are based on the functional insufficiency of veins distributed in the corpus cavernosum. That is, due to an insufficient extent of the relaxation of corpus cavernosum, the pressure within the corpus cavernosum cannot be increased to such an extent that its leakage into penile vein can be prevented. ${ }^{5}$ The pathophysiological etiology of the erectile dysfunction originates from the nerve injury that is caused during prostatectomy. Even after a nerveconserving operation, the erectile dysfunctions do frequently occur. One cause of these erectile dysfunctions is the physiologic nerve block as known the neuropraxia and the other is penile fibrosis after hypoxemia. ${ }^{5,6,21}$ The injury of nerves innervating corpus cavernosum was developed during the dissection of prostate, which caused the physiologic nerve block and the postoperative occurrence of erectile dysfunction, thereof. ${ }^{5,6}$ On recent prospective study of nerve-sparing radical prostatectomy patients, postoperative prophylactic PGE1 were more likely to improve erectile function than placebo. ${ }^{22}$ In this study, although psychogenic effects cannot be ruled out, up to $28 \%$ of patients in one study using intracorporal PGE1 achieved improved spontaneous erections and less frequent need for intracorporal injections. Taken together, this study suggests a role of hypoxemia in penile fibrosis and a role for and in preserving a functional 
SM/connective tissue balance in the corpus cavernosum. The authors thought the muscle/collagen ratio is important for the erectile function. In our study, the ICP and muscle/collagen ratio of nerve injury group were lower than mirodenafiladministered groups and these results indirectly improved that. Conclusively, due to a depletion of oxygen supply within the corpus cavernosum and the occurrence of fibrosis of corpus cavernosum, venous-blocking erectile dysfunction eventually occurs. Because erectile dysfunction after the prostatectomy may lower the quality of life consequently, many patients refuse to receive the surgery. Recent studies have reported that a long-term use of PDE5 inhibitor showed effectiveness among patients who complained of erectile dysfunction after the prostatectomy. ${ }^{7,8}$ Also, there were animal studies that attempted to show the effects of the PDE5 inhibitors in treating the erectile dysfunction. ${ }^{9}$ These results proposed the possibility that a recovery of erectile function could be achieved by preventing NOS-induced fibrosis and increasing muscle fibers after the prostatectomy. Monica and co-workers ${ }^{9}$ dissected bilateral corpus cavernosum nerves in rats and resected ancillary branches at a length of $5 \mathrm{~mm}$, thereby creating an animal experimental model of erectile dysfunction that was similar to that seen after prostatectomy. The dose of vardenafil corresponding to $20 \mathrm{mg}$ in humans was calculated based on the surface area of rats. This was followed by a 45-day administration. ICP was measured 45 days later, which showed that the drop rate was $42 \pm 5 \mathrm{~mm} \mathrm{Hg} \mathrm{min}^{-1}$ in the nerve injury group, $18 \pm 2$ in the control group and $17 \pm 2$ in the vardenafil treatment group. In our study, the results showed that ICP of the nerve injury group $(7 \pm 1.1 \mathrm{~mm} \mathrm{Hg})$ decreased $(9 \pm 2.2 \mathrm{~mm} \mathrm{Hg})$ and the drop rate increased compared with the control group (nerve injury group, $31 \pm 2.3 \mathrm{~mm} \mathrm{Hg} \mathrm{min}^{-1}$; control group $9 \pm 1.5 \mathrm{~mm} \mathrm{Hg})(P<0.05)$. The results also showed that ICPs of mirodenafil-administered groups $(11 \pm 2.0$ and $14 \pm 2.4 \mathrm{~mm} \mathrm{Hg})$ increased and drop rates decreased compared with the nerve injury group $(P<0.05)$. These results indicate that the administration of PDE5 inhibitor group showed a remarkable improvement in the erectile function. On the Masson's trichrome staining, an increase in the muscle fibers present within corpus cavernosum and a decrease in collagen synthesis were observed. ${ }^{9}$ In our study, mirodenafil-administered groups' muscle/collagen ratio was increased compared to the nerve injury group. These results were also in agreement with the studies mentioned above, which were indicative of the effects of PDE5 inhibitor after the nerve injury. The presumptive mechanisms are based on the increased synthesis of cGMP and the resulting decrease of auto-apoptosis of muscle cells and prevention of collagen deposition. According to the experiments performed by Monica and co-workers, ${ }^{9}$ however, the nerve was dissected and the secretion of NOS was impossible on a theoretical basis. Nevertheless, the causative factors explaining these phenomena could not be identified. It has been hypothesized that they originated from the nerve regeneration and the effects of materials that have not been disclosed up to present. In our study, the nerve dissection was not performed and the nerve injury was only conducted by the compression, which were different from the experimental results reported by Monica and co-workers. ${ }^{9}$ Henceforth, further studies are warranted to examine the results after the nerve dissection.

\section{Conclusion}

In our study, the nerve injuries on both sides of corpus cavernosum significantly reduced the erectile function and expression level of NOS and cGMP. After the administration of mirodenafil, the erectile function and the expression of NOS and cGMP were improved. These results serve as the foundation for the future mirodenafil treatment of postprostatectomy erectile dysfunction patients.

\section{Conflict of interest}

There was no ethical problem in this animal study and we obtained the approval of Institutional Review Board (IRB) in Ujungbu St Mary's hospital and the number is UJA2009-14A. We acknowledge the financial support of the Catholic Institute of Cell Therapy Basic Science Programs Foundation made in the program year of 2009.

\section{References}

1 Yee DS, Ahlering TE. Radical prostatectomy: a current perspective. J Urol 2007; 178: 376-377.

2 Benoit RM, Naslund MJ, Cohen JK. Complications after radical retropubic prostatectomy in the medicare population. Urology 2000; 56: 116-120.

3 Marien TP, Lepor $H$. Does a nerve-sparing technique or potency affect continence after open radical retropubic prostatectomy?. BJU Int 2008; 102: 1581-1584.

4 Ahlering TE, Roddriquez E, Sharecky DW. Overcoming obstacles: nerve-sparing issues in radical prostatectomy. J Endourol 2008; 22: 745-750.

5 Dubbleman YD, Wildhagen MF, Dohle GR. Penile vascular evaluation and sexual function before and after radical retropubic prostatectomy: 5-year follow up. Int J Androl 2008; 31: 483-489.

6 Ohebshalom M, Parker M, Waters B, Flanagan R, Mulhall JP. Erectile haemodynamic status after radical prostatectomy correlates with erectile functional outcome. BJU Int 2008; 102: 592-596.

7 Carson CC, Lue TF. Phosphodiesterase type 5 inhibitors for erectile dysfunction. BJU Int 2005; 96: 257-280.

8 Namiki S, Kwan L, Kagawa-singer M, Arai Y, Litwin MS. The effect of erectile function on the use of phosphodiesterase-5 inhibitor after radical prostatectomy in Japanese and U.S. men. Urology 2008; 71: 901-905. 
9 Ferrini MG, Davila HH, Kovanecz I, Sanchez SP, GonzalezCadavid NF, Rajfer J. Vardenafil prevents fibrosis and loss of corporal smooth muscle that occurs after bilateral cavernosal nerve resection in the rat. Urology 2006; 68: 429-435.

10 Lee SK, Kim Lee SK, Kim Y, Kim TK, Im GJ, Lee BY et al. Determination of Mirodenafil and sildenafil in the plasma and corpus of SD male rats. J Pharm Biomed Anal 2009; 49: 513-518.

11 Choi YH, Lee YS, Bae SH, Kim TK, Lee BY, Lee MG. Dosedependent pharmacokinetics and first-pass effects of Mirodenafil, a new erectogenic, in rats. Biopharm Drug Dispos 2009; 30: $305-317$.

12 Jung JY, Kim SK, Kim BS, Lee SH, Park YS, Kim SJ et al. The penile erection efficacy of a new phosphodiesterase type 5 inhibitor, Mirodenafil (SK3530), in rabbits with acute spinal cord injury. J Vet Med Sci 2008; 70: 1199-1204.

13 Paick JS, Ahn TY, Choi HK, Chung WS, Kim JJ, Kim SC et al. Efficacy and safety of Mirodenafil, a new oral phosphodiesterase type 5 inhibitor, for treatment of erectile dysfunction. J Sex Med 2008; 5: 2672-2680.

14 Andersson KE. Neurophysiology/pharmacology of erection. Int J Impot Res 2001; 13(Suppl 3): S8-S17.

15 Heaton JP. Central neuropharmacological agents and mechanisms in erectile dysfunction: the role of dopamine. Neurosci Biobehav Rev 2000; 24: 561-569.

16 Becker AJ, Uckert S, Stief CG, Scheller F, Knapp WH, Machtens SA et al. Systemic and cavernous plasma levels of vasoactive intestinal polypeptide during sexual arousal in healthy males. World J Urol 2002; 20: 59-63.
17 Palmer RM, Ferrige AG, Moncada S. Nitric oxide release accounts for the biological activity of endothelium-derived relaxing factor. Nature 1987; 327: 524-526.

18 Dusting GJ. Nitric oxide in cardiovascular disorders. J Vasc Res 1995; 32: 143-161.

19 Ferrini MG, Kovanecz I, Nolazco G, Rajfer J, Gonzalez-Cadavid NF. Effects of long-term treatment with vardenafil on the development of the fibrotic plaque in a rat model of Peyronie's disease. BJU Int 2006; 97: 625-633.

20 Gonzalez-Cadavid NF, Rajfer J. The pleiotropic effects of inducible nitric oxide synthase on the physiology and pathology of penile erection. Curr Pharm Des 2005; 11: 4041-4046.

21 Moreland RB. Is there a role of hypoxemia in penile fibrosis: a viewpoint presented to the Society for the Study of Impotence. Int J Import Res 1998; 10: 113-120.

22 Montorsi F, Guazzoni G, Strambi LF, Da Pozzo LF, Nava L, Barbieri L et al. Recovery of spontaneous erectile function after nerve-sparing radical retropubic prostatectomy with and without early intracavernous injections of Alprostadil: results of a prospective randomized trial. J Urol 1997; 158: $1408-1410$.

(c) This work is licensed under the Creative

SOMERRIHISRESERVED Commons Attribution-NonCommercial-No

Derivative Works 3.0 Unported License. To view a copy of this license, visit http://creativecommons.org/licenses/ by-nc-nd/3.0/ 